Article

\title{
Exploring the Factors Influencing Expansion of Nuclear Energy in Croatia
}

\author{
Krešimir Trontl *(D), Mario Matijević (D), Dubravko Pevec (D) and Radomir Ječmenica
}

Citation: Trontl, K.; Matijević, M.; Pevec, D.; Ječmenica, R. Exploring the Factors Influencing Expansion of Nuclear Energy in Croatia. Energies 2021, 14, 8022. https://doi.org/ $10.3390 /$ en 14238022

Academic Editor: Donato Morea

Received: 11 November 2021 Accepted: 23 November 2021 Published: 1 December 2021

Publisher's Note: MDPI stays neutral with regard to jurisdictional claims in published maps and institutional affiliations.

Copyright: (c) 2021 by the authors. Licensee MDPI, Basel, Switzerland. This article is an open access article distributed under the terms and conditions of the Creative Commons Attribution (CC BY) license (https:/ / creativecommons.org/licenses/by/ $4.0 /)$.
Faculty of Electrical Engineering and Computing, University of Zagreb, 10000 Zagreb, Croatia; mario.matijevic@fer.hr (M.M.); dubravko.pevec@fer.hr (D.P.); radomir.jecmenica@fer.hr (R.J.)

* Correspondence: kresimir.trontl@fer.hr; Tel.: +385-1-6129-670

Abstract: Nuclear energy is an option that enables a significant reduction of greenhouse gases emissions at the national and European Union (EU) level. However, it is also an option that is mostly influenced by public opinion and an option that has strong cross-border impact. Croatia does not consider nuclear options, but a possible future turn to nuclear might have an influence on other EU countries. The possibility for such a turn is analyzed, taking into account public opinion as well as historical and economic factors. Based on the results of a public opinion survey, it can be deduced that the Croatian public is not inclined to nuclear energy and considers it a risky option, although nuclear power plants in neighboring countries are not perceived as a high-risk threat. Trust in government as an information source is very low. Despite historical aspects that suggest scientific and expert knowledge capable of handling nuclear build, public opinion and the low economic framework indicate that a turn a to nuclear in Croatia is highly unlikely.

Keywords: public opinion; energy policy; Croatia; nuclear option; history; economy

\section{Introduction}

A number of experts consider the application of fission nuclear energy for electricity generation as a technology with a minimal $\mathrm{CO}_{2}$ footprint [1,2]. Even green activists known for negative attitudes toward nuclear technology in the past are now expressing opposite beliefs and supporting the nuclear option as a strong tool for combating climate changes [3]. However, in the eyes of the public and consequently in the response of the policy-makers, nuclear technology experiences frequent ups and downs. The European Union (EU) is particularly interesting because of two levels of energy strategy planning, European and national, which are both strongly influenced by public opinion.

In December 2019, the EU leaders agreed that nuclear energy will be recognized as a part of the solution toward a $\mathrm{CO}_{2}$-neutral economy by 2050: "The European Council acknowledges the need to ensure energy security and to respect the right of the Member States to decide on their energy mix and to choose the most appropriate technologies. Some Member States have indicated that they use nuclear energy as part of their national energy mix" [4]. However, in Article 5 of the Just Transition Fund (JFT) proposal dated January 2020, which is envisioned as the main tool to support the territories mostly affected by the transition toward climate neutrality, the decommissioning and the construction of the new nuclear power plants are specifically excluded from the JFT financial support [5]. Therefore, the possible construction of new nuclear power plants (NPP) or keeping the existing NPPs operational is the sole responsibility and decision of the national governments. Out of 27 EU countries, 13 have operational NPPs (106 units) or NPPs under construction (four units) [6]. In general, when considering official governments' positions, EU countries can be divided into four categories:

1. Countries that have operational NPPs but are in the process of phase out: Belgium by 2025, Germany by 2022, Netherlands at the end of the one operational NPP's lifetime, Spain by 2035, and Sweden by 2050; 
2. Countries that do not have operational NPPs and are not considering nuclear options for the future: Austria, Croatia (does not have an operational NPP on its territory but owns $50 \%$ of NPP Krško located in Slovenia), Cyprus, Denmark, Greece, Ireland, Italy, Luxemburg, Malta, Portugal;

3. Countries that have operational NPPs and plan to boost their nuclear fleet: Bulgaria, Czech Republic, Finland, Hungary, Romania, Slovakia, and Slovenia;

4. Countries that do not have operational NPPs but have plans to build in the future or consider the implementation of nuclear option: Estonia (working group to investigate nuclear option formed in November 2020 [7]), Lithuania, Latvia (all three Baltic states are involved in negotiations dated from 2007 and initially including Poland, which withdrew from the project in 2011 to build NPP in Lithuania but the future of the project is unclear), Poland.

France holds a unique position and cannot be classified in any of the aforementioned categories. It operates 56 reactors with one under construction. Nuclear share in electricity generation is $71 \%$ with reliable and low-cost production enabling high electricity export, reaching up to the value of 3 billion Euros per year. Nevertheless, the French government plans to decrease the nuclear share to $50 \%$ by 2035 .

The European Union is a complex entity with a two-way communication and dependency. Decisions made by the EU influence national policies, but also, national policies have an impact on EU strategies. The ability to predict possible changes in national policy is important for long-term energy planning on the EU level. Croatia is a small part of the EU, with just a $1 \%$ share in the EU population and a roughly $0.37 \%$ share in the overall EU-27 Gross Domestic Product (GDP) for 2020 [8], but nevertheless, possible changes in the Croatian energy strategy might influence the rest of the Europe. There are many factors to be considered when weighing the nuclear option in the energy mix, including historical, political, social, and economic aspects. Public opinion and public participation have long been recognized as one of the pillars in the decision-making process, together with stakeholders and experts [9]. The purpose of the conducted research is to explore the factors influencing the possibility of nuclear energy expansion in Croatia. Although historical and economic factors are briefly addressed, we mainly focus on public opinion regarding nuclear energy in Croatia.

The main hypotheses of the research are as follows:

1. The Croatian public is not inclined to the nuclear option;

2. Nuclear power plants in neighboring countries have a negligible influence on the public;

3. The public generally feels poorly informed and lacks trust in the government.

Taking into account historical, economic, and mainly findings from public opinion research, the conclusions on the prediction of nuclear energy incorporation in the Croatian energy mix will be formulated. Our findings and conclusions might help national and EU policy makers in long-term energy strategy planning.

Rather similar studies have been recently conducted for India [10], China [11], and Indonesia [12]. The results of these studies can give implications and be used as references for governmental nuclear energy policies.

\section{Methodology}

The methodology used in the research is depicted in Figure 1. The main focus and guideline of the methodology is the public opinion survey on nuclear energy in Croatia, its preparation, implementation, analysis of the results, and their interpretation. 


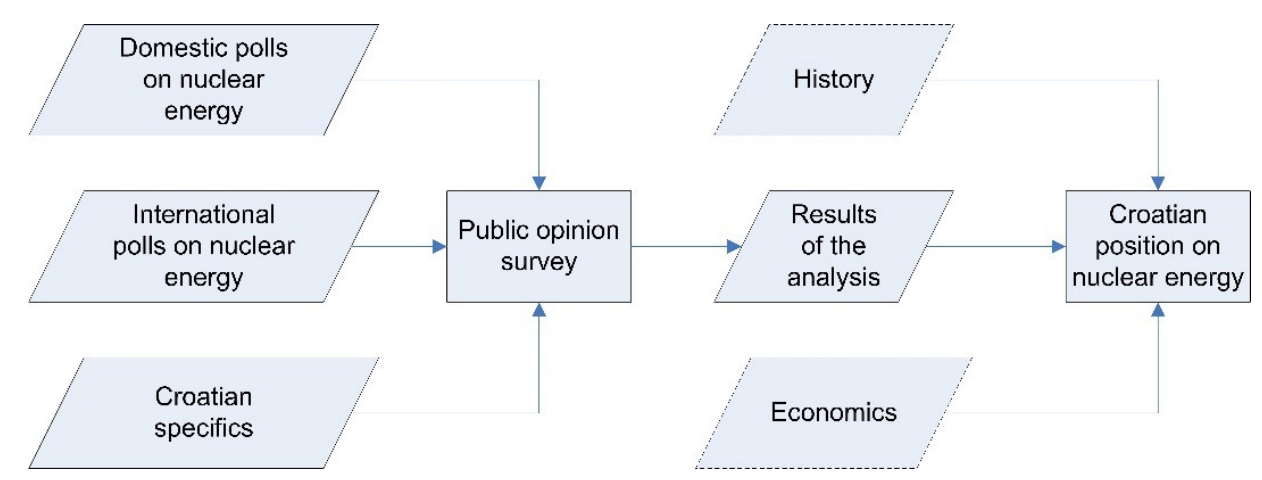

Figure 1. Methodology of the research.

The preparation of the survey questionnaire, which is described in more detail in Section 2.1, is based on the study of domestic and international polls on nuclear energy subjects conducted in the past. Analysis of the Croatian specifics was required to adjust the questions for the Croatian population.

The foundations of the survey implementation have been stratified sampling of the targeted population and face-to-face interviews. More details on survey implementation are given in Section 2.2. Apart from the analysis and interpretation of survey results, to estimate the current and future Croatian position on nuclear energy, it was also necessary to account for historical and economic factors. A deep study of Croatian history and economics influencing its position on nuclear energy is beyond the scope of this article. Therefore, we just briefly emphasize the most important elements.

\subsection{Bases for Survey Questionnaire}

There are a number of international surveys oriented toward nuclear energy subjects. However, taking into account that Croatia is a European country, the Eurobarometer survey "Europeans and nuclear safety" [13] has been taken as the primary international survey to serve as the basis for the preparation of Croatian public opinion survey. This will also enable comparison of the position of the Croatian public with that of other Europeans. However, it has to be noted that the Eurobarometer survey took place almost a decade before the envisioned Croatian survey and also prior to the Fukushima accident. Nuclear energy is closely related to the management of radioactive waste. Therefore, the decision was made to prepare a survey comprised of questions related to both subjects, nuclear energy as well as management of radioactive waste. The Eurobarometer survey "Attitudes towards radioactive waste" [14] has been chosen as the international base for the latter subject.

To the best of our knowledge, a classical national Croatian survey on nuclear energy has never been conducted prior to our research. The closest one was the online survey carried out in 2012 exclusively on the subject of radioactive waste [15]. As far as nuclear energy is concerned, a number of surveys have been carried out in the past aiming specifically at high school students primarily from the Croatian capital Zagreb and two neighboring counties [16], and students from the University of Zagreb [17]. Despite overwhelming information originating from the surveys due to the narrow focus of the targeted population, conclusions on the position of general population could not be reached with satisfying precision. However, these surveys were used to identify elements that are specific for Croatia. Gained knowledge was used to form questions for the envisioned survey.

\subsection{Survey Implementation}

The main goal of the research was to gain knowledge on the position of the Croatian population toward nuclear energy and radioactive waste. As it was not practically feasible to survey the entire population, an appropriate sampling process had to be applied. There are four main stages in the sampling process: clear definition of the target population, 
selection of the sampling frame, selection of the sampling technique, and determination of the sample size [18].

The target population was all Croatian citizens. Analysis of the Eurobarometer surveys mentioned earlier has shown that both of them targeted the population aged 15 and over. To enable straightforward comparison of the Croatian survey results to the results of Eurobarometer surveys, the same age constraint has been applied, defining a new population subset, i.e., a sampling frame of Croatians 15 years old and older: altogether $3,632,461$ individuals based on the national census from 2011 [19].

In general, there are two categories of sampling techniques, namely probability sampling and non-probability sampling, each one comprised of a number of specific techniques. Taking into account their strengths and weaknesses [18], proportional stratified random sampling has been selected as the technique of choice. The sampling frame has been divided into subsets (strata) based on regional (20 counties plus the capital of Zagreb with administrative rights equal to the county ones), gender (male and female), educational (five educational levels ranging from "Without primary school" to "University level education"), and age (four age intervals) keys.

The sample size and the desired confidence level impact the statistical interpretation of the results expressed through margin of error (MOE). For the normal distribution and $95 \%$ confidence level, the MOE experiences a steep decrease as the sample size increases up to a certain point, after which the decrease enters the form of a saturation curve (Figure 2) [20,21].

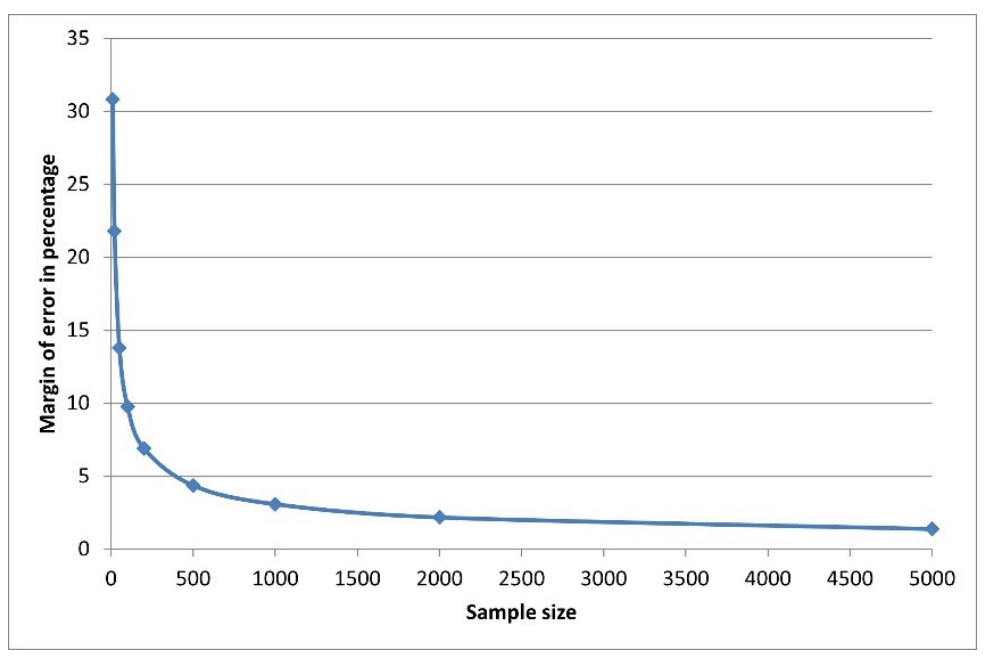

Figure 2. Margin of error as a function of the sample size for a $95 \%$ confidence level and $50 \%$ proportion percentage.

The optimization of the desired reliability of survey results and financial as well as personnel capabilities of the research team led to the selection of the sample size of 2000. Rescaling of the targeted population subset to the desired sample size resulted in real numbers, which had to be manually rounded to integers. For example, in the Croatian population, there are 3,632,461, individuals 15 years old or older, 1,731,610 males and 1,900,851 females. Rescaling to the sample size of 2000 results in 953.4 males and 1046.6 females. The similar situation was faced for all strata-based rescaling. Manual rounding to integers for all strata resulted in the final sample size of 2002 having the same percentage per different categories within strata as the overall targeted population. The downside of the sampling process was the decrease in the number of intended survey participants in certain counties for particular categories. For example, the smallest county in Croatia, based on the number of inhabitants, is Ličko-senjska county, leading to the smallest number of intended survey participants, only 12 males and 13 females. Out of 12 males, one had to be 15-24 years of age who had finished high school, three had to be 
25-39 years of age, one who had finished primary school and two who had finished high school, etc. Having in mind the relationship between the MOE and the sample size, apart from the overall population, only gender categories (955 male and 1047 female participants) have sample sizes large enough for the MOE to be satisfactory (Table 1). Therefore, when analyzing the survey results, we will focus on these three sets. However, the qualitative comparison of the different groups' attitudes is possible, especially if large differences are observed. Therefore, such interesting deviations will be mentioned.

Table 1. MOE for different survey results [\%] [20,21].

\begin{tabular}{cccccc}
\hline Sample Size & $\begin{array}{c}\text { Survey } \\
\text { Result } \\
\mathbf{1 0 \%} \text { or } \mathbf{9 0 \%}\end{array}$ & $\begin{array}{c}\text { Survey } \\
\text { Result } \\
\mathbf{2 0 \%} \text { or } \mathbf{8 0} \%\end{array}$ & $\begin{array}{c}\text { Survey } \\
\text { Result } \\
\mathbf{3 0 \%} \text { or } \mathbf{7 0} \%\end{array}$ & $\begin{array}{c}\text { Survey } \\
\text { Result } \\
\mathbf{4 0 \%} \text { or } \mathbf{6 0 \%}\end{array}$ & $\begin{array}{c}\text { Survey } \\
\text { Result } \\
\mathbf{5 0 \%}\end{array}$ \\
\hline Overall 2002 & 1.31 & 1.74 & 2.00 & 2.14 & 2.18 \\
Male 955 & 1.89 & 2.52 & 2.89 & 3.09 & 3.16 \\
Female 1047 & 1.81 & 2.41 & 2.76 & 2.95 & 3.01 \\
\hline
\end{tabular}

The survey itself has been carried out using the face-to-face method with members of the research team interviewing survey participants who were randomly selected. The research teams visited every county, approached potential candidates, and after receiving willingness confirmation asked initial questions to place the candidate in the appropriate categories (gender, age, education). If the quota for the particular category had been fulfilled, the interview was canceled. The interviews lasted approximately $10 \mathrm{~min}$. Overall survey data have been merged in a report in Croatian languge [22].

As indicated before, the survey covered both nuclear energy-related questions as well as the questions oriented toward radioactive waste management (RWM). The survey results on the RWM topic have been published in a separate article [23]. Both topics are closely related and should be jointly analyzed. However, that type of analysis is highly demanding in space, particularly taking into account that the survey consisted of 10 nuclearoriented questions and 3 RWM-oriented questions, many having multiple sub-questions. Therefore, in Section 3, we present only the detailed results of the survey analyses for selected questions in nuclear energy topic and give a brief summary of RWM issues and the remaining nuclear-oriented questions. Preliminary findings for all nuclear-oriented questions have been presented at the Slovenian Nuclear Society International Conference NENE 2017 [24].

\section{Results of the Survey Analyses}

The survey consisted of ten questions oriented on the topic of nuclear energy, three questions on the RWM topic, and five inter-topic questions mostly on information pathway aspects. Selection of the most interesting findings is presented in the proceeding subsections.

\subsection{The Term "Nuclear Power Plant"}

When asked to express their opinion on the term "Nuclear power plant" by selecting one out of five offered answers (see Figure 3), 48.4\% of survey participants chose "The risk is greater than the advantage", while $27.1 \%$ had the opposite opinion. The females were slightly more inclined to the belief that nuclear power plants are more risky than advantageous (50.0\% females versus $46.8 \%$ males), while the males emphasized the advantages over risk in greater percentage than the females (32.9\% males versus $21.9 \%$ females). 


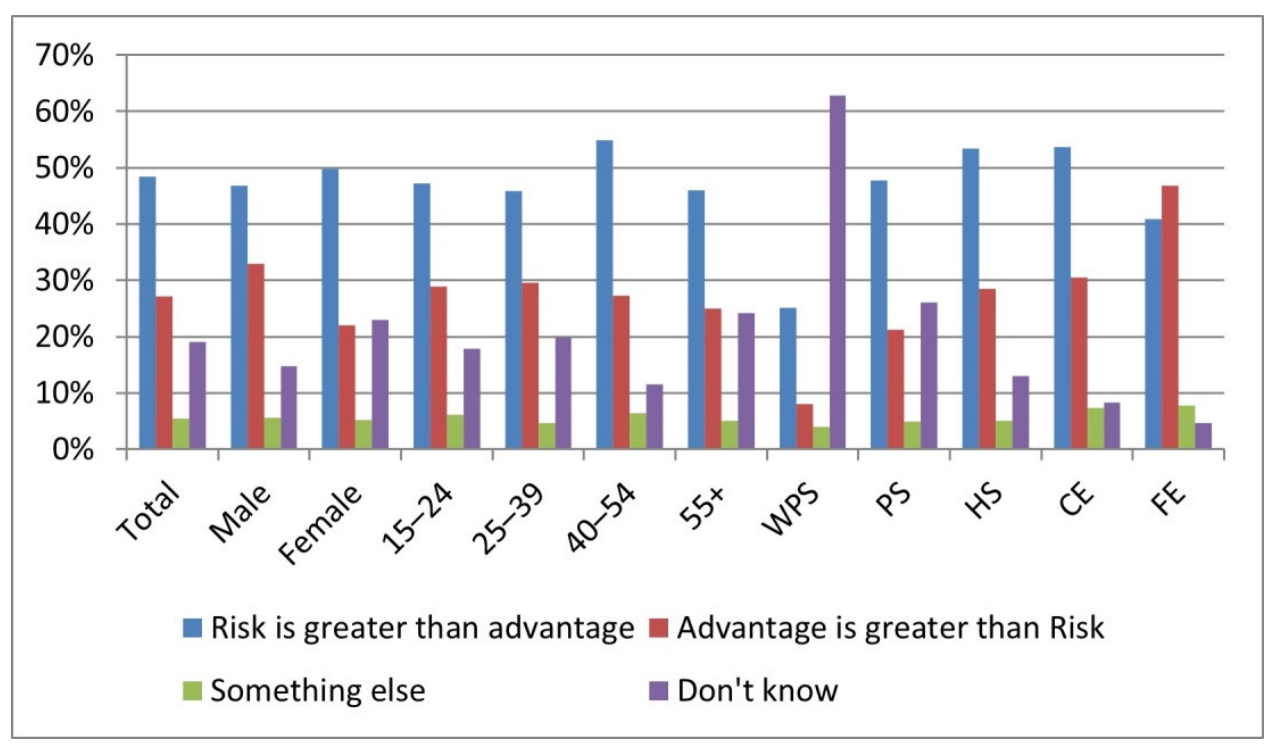

Figure 3. The nuclear power plants-a risk or an advantage (WPS-without primary school, PSprimary school, HS-high school, CE-college education, FE-faculty education).

As previously pointed out, the uncertainties associated with regional, educational, and age distribution of opinions are higher than the one linked to gender. However, it is interesting to notice that only in one small eastern located Croatian county having approximately $3.5 \%$ of the national targeted population (Brodsko-posavska county), the overall support for nuclear is higher than that of the opposition, with more males approving it and less females disapproving it compared to national values. The deviation of negative attitudes toward nuclear power plants in comparison to the national average $(48.4 \%)$ is depicted in Figure 4, where the locations of the two nuclear power plants closest to Croatia are also given.

Within all age categories, independently of gender, the prevailing position is that the nuclear power plants are more risky than advantageous. For both females and males, the maximum risk perception was observed in the category $40-54$ years of age $(59.8 \%$ and $50.2 \%$, respectively). As far as educational categorization is concerned, only the group of male participants with finished faculty believes that nuclear power plants are more advantageous than risky ( $53.3 \%$ compared to $35.5 \%)$.

Particularly interesting are the shares of participants selecting the answer "Don't know" over different categories. As expected, the shares decrease as the level of knowledge increases, from $62.9 \%$ for participants without primary school down to $4.6 \%$ for facultyeducated participants. The overall $19.1 \%$ of participants who do not know whether NPPs are a risk or an advantage indicates a possible lack of proper knowledge and/or information required to draw conclusions. When compared to the Eurobarometer 2010 survey [13], the share of "Don't know" participants is much higher than the EU average of 7\% (comparable only to residents of Ireland, Malta, Romania, and Portugal). Croatian participants are below the EU average for both main options: the risk is greater than the advantage ( $48 \%$ versus $51 \%$ ) as well as that the advantage is greater than the risk ( $27 \%$ versus $35 \%$ ). 


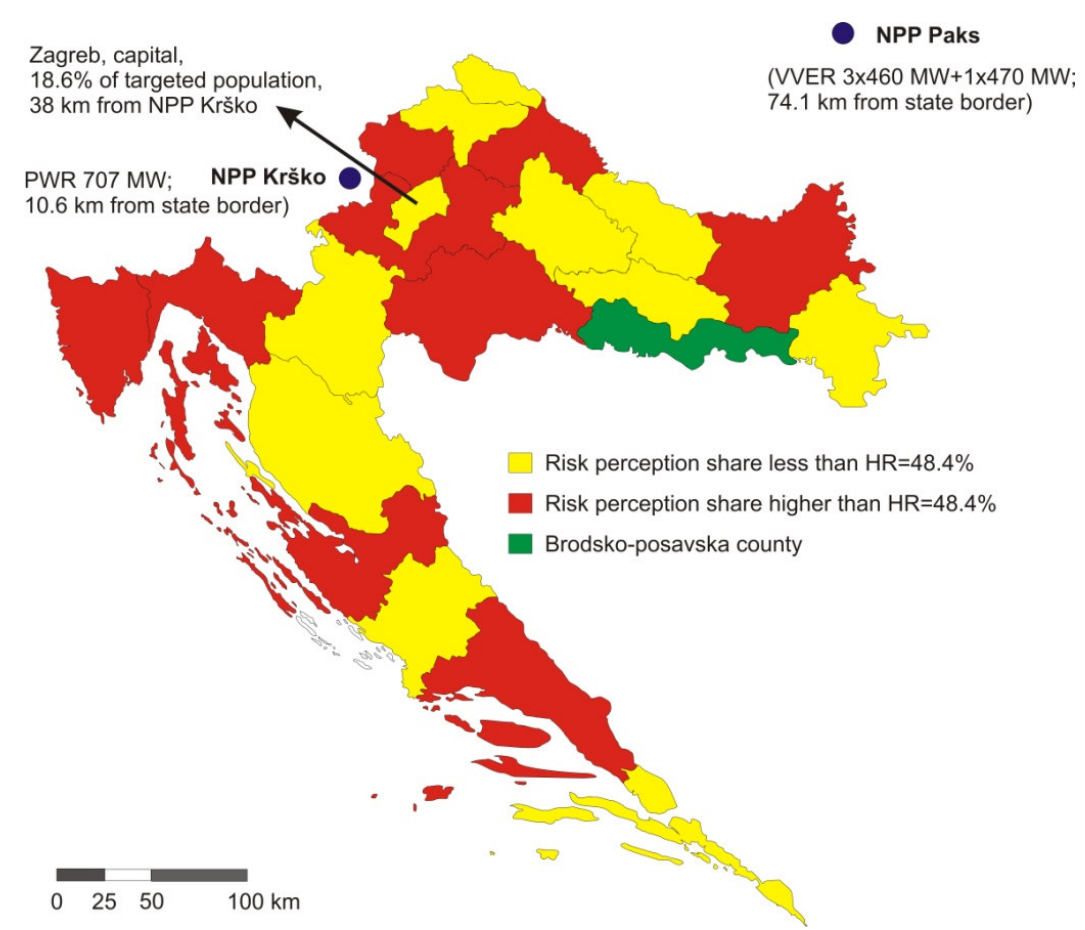

Figure 4. Regional distribution of risk perception from nuclear power plants with respect to national level.

\subsection{General Position toward Nuclear Energy}

The survey participants were asked to express their opinion on nuclear energy in general by selecting one out of five offered answers (Figure 5). Only $6.9 \%$ expressed full support to nuclear energy, with an additional 33.3\% expressing partial support. Partial and full opposition toward nuclear energy was expressed by $19.6 \%$ and $20.3 \%$ of the participants, respectively. Approximately one-fifth of the participants selected the answer "Neutral". Partial or full support for nuclear energy was expressed slightly more by males, especially in younger age categories. On the other hand, the elders are more opposed to nuclear energy than the younger participants, while the neutral attitude is more expressed by the females than by the males. Detailed shares are given in Figure 5 .

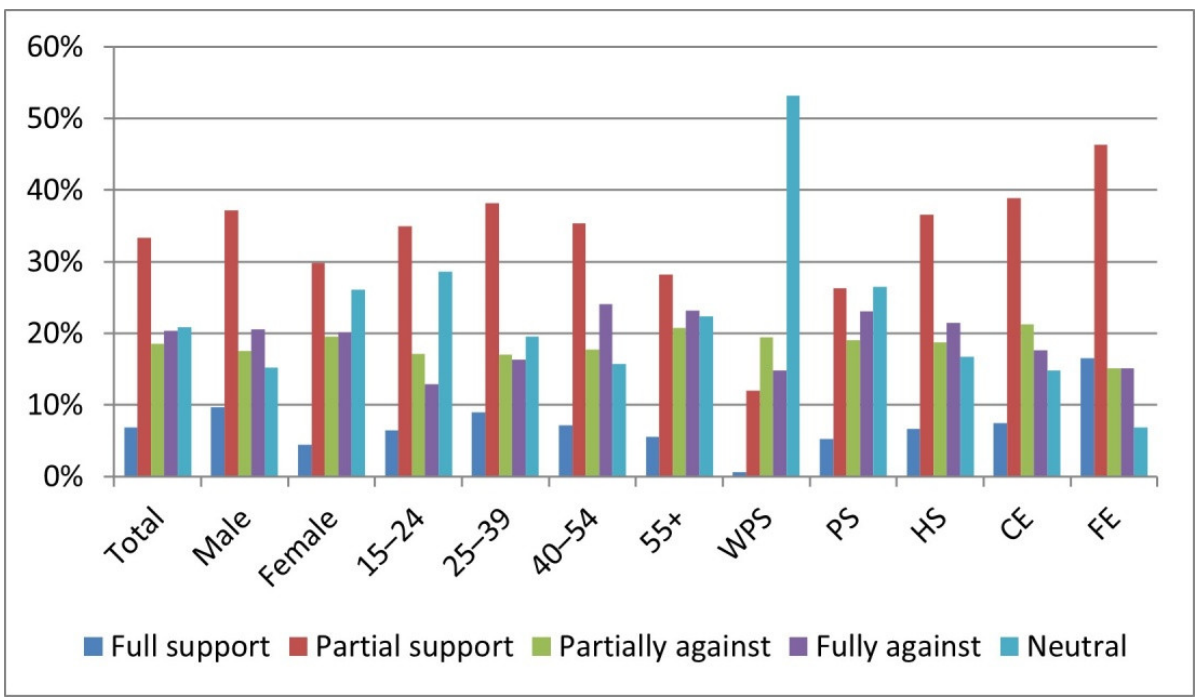

Figure 5. General position toward nuclear energy (WPS-without primary school, PS-primary school, HS-high school, CE-college education, FE-faculty education). 
With smaller deviations, the support for nuclear energy for both genders increases with the level of education, while the percentage of neutral participants decreases. The influence of education on the percentage of opposing participants is not so strongly emphasized.

Analysis of participants' position in respect to regional category indicates that in nine out of 21 counties, the majority of participants support nuclear, while in the remaining eleven counties, the majority is against nuclear energy in general. However, only in four counties all together, the position of participants might be interpreted as a definite one. In the rest of the counties, the share of "neutral" participants is larger than the absolute difference between supportive and non-supportive shares, indicating the possibility of a balance shift (Figure 6).

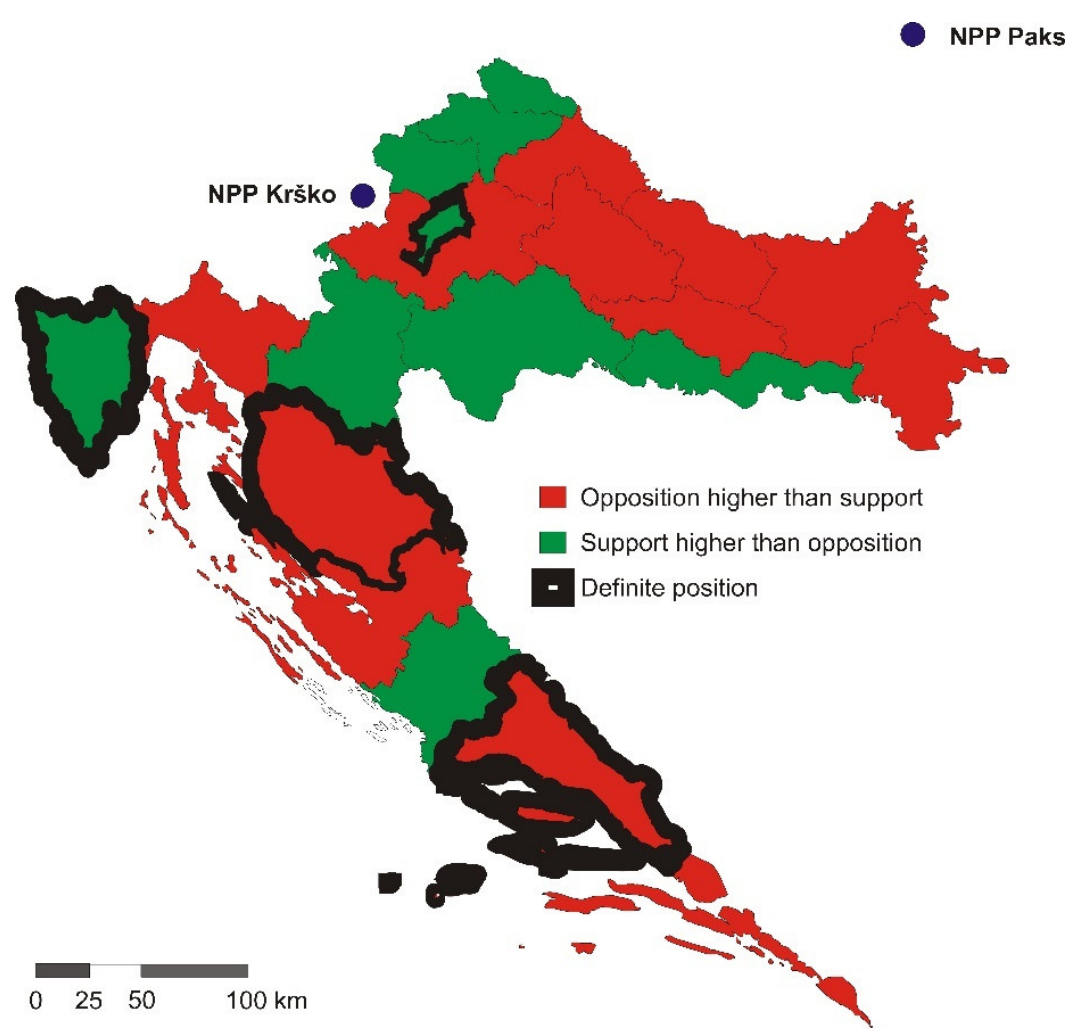

Figure 6. Regional distribution of general position toward nuclear energy.

The cross-referencing of answers to the first two questions shows that $80.7 \%$ of participants who support nuclear energy also believe that nuclear power plants have more advantages than risks. In addition, the majority of those who believe that the risk of nuclear is greater than its advantages do not support nuclear energy (Table 2).

Table 2. Support for nuclear vs. risk perception.

\begin{tabular}{cccc}
\hline & Support & Against & Neutral \\
\hline Advantage is greater than risk & $80.70 \%$ & $9.01 \%$ & $10.29 \%$ \\
Risk is greater than advantage & $26.65 \%$ & $61.67 \%$ & $11.67 \%$ \\
Something else & $37.04 \%$ & $49.07 \%$ & $13.89 \%$ \\
Don't know & $17.80 \%$ & $20.94 \%$ & $61.26 \%$ \\
\hline
\end{tabular}

The comparison of the survey results with the Eurobarometer survey [14] reveals that Croatian participants are below the EU average for support as well as for opposition to nuclear energy (Croatian support of 40\% versus EU 44\%; Croatian opposition of 39\% compared to EU 45\%). The percentage of Croatian participants selecting the answer "Neutral" is almost twice as much as the EU average (21\% compared to $11 \%$ ). 


\subsection{Should Croatia Build a Nuclear Power Plant?}

The survey participants were asked to express their support or dispute to several claims related to nuclear power plants (Figure 7). More than half of the participants fully or partially support the usage of the NPPs for electricity production $(21.9 \%$ and $33.5 \%$, respectively), while approximately one-third of the participants fully or partially dispute that idea (11.3\% and $19.3 \%$, respectively). However, general support for nuclear generated electricity drastically decreases when the possibility of NPP being built in Croatia is considered. Three possible reasons for NPP construction have been graded by the participants. The construction of the Croatian NPP for the reason of a country's energy independency got the highest support of slightly more than one-third of the participants (13.3\% full support and 22.2\% partial support). A close second was the necessity to build an NPP to prevent an electricity shortage with an overall support of $32.1 \%$. Building of the NPP for some other, unidentified reason had the support of only $16.6 \%$ of the participants. It should be noted that the share of participants selecting the answer "Don't know" was particularly high in case of unidentified cause being offered as a reason for building NPP.

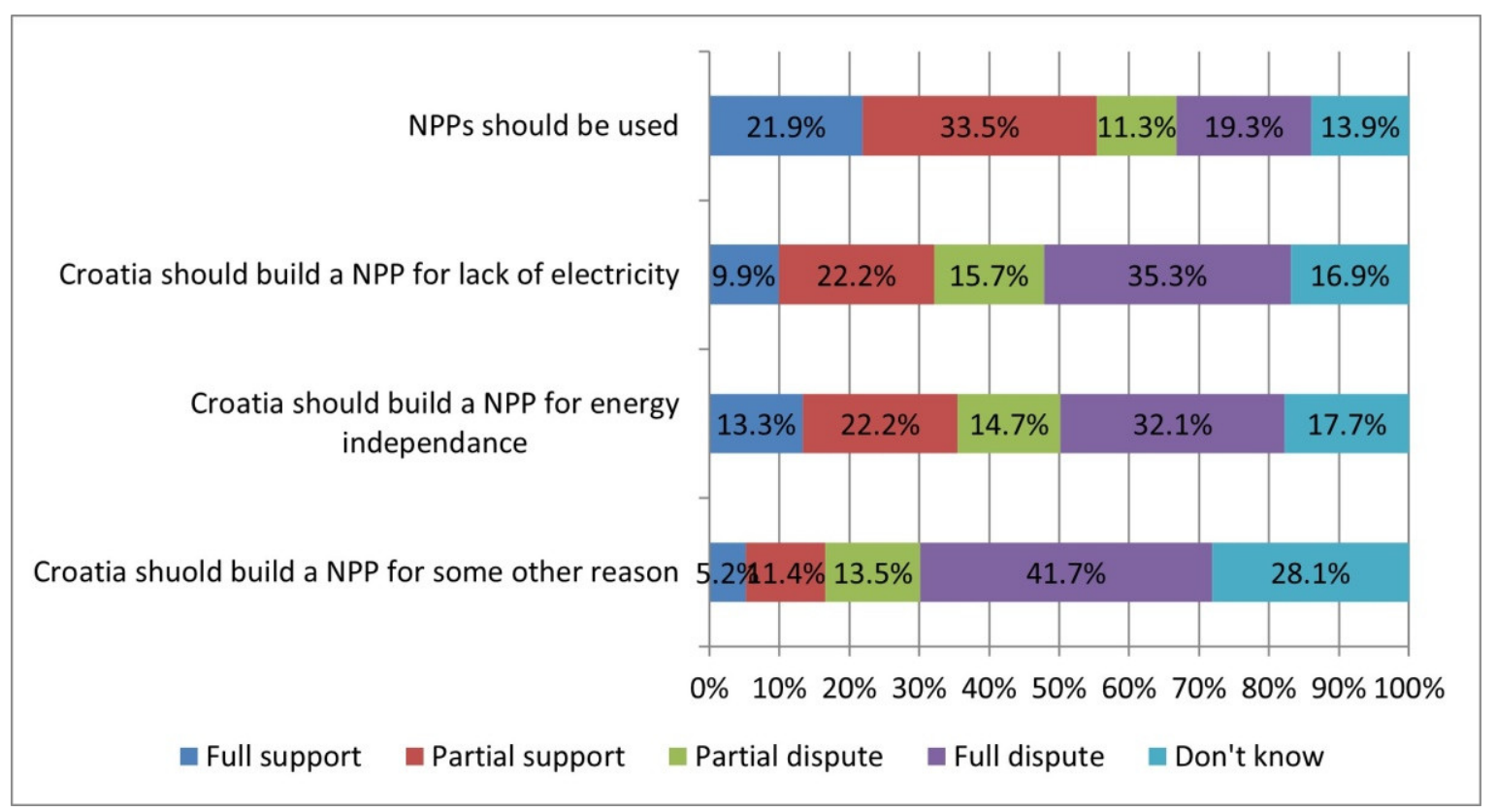

Figure 7. Should NPPs be used and should Croatia build one?

It is interesting to cross-reference the general position of the participants toward nuclear energy (Section 3.2) and support for a possible NPP being built in Croatia. Approximately $30 \%$ of the participants that support nuclear energy are against the construction of the NPP in Croatia for lack of electricity or energy independency. The share increases to more than $45 \%$ for some other, unidentified, construction reason. It seems rather clear that the Not In My Back Yard (NIMBY) phenomenon is detectable in this case.

On the other hand, roughly $15 \%$ of the participants that are against nuclear energy are rather pragmatic and would support the construction of the Croatian NPP for the energy independency reason.

\subsection{Risk from the Nuclear Power Plants in Neighboring Countries?}

As already shown in Figure 4, there are two nuclear power plants located closely to Croatian borders, NPP Krško in Slovenia (1 PWR, 707 MW) and NPP Paks in Hungary (4 VVER, all together $1850 \mathrm{MW}$ ). NPP Krško is $10.6 \mathrm{~km}$ away from the border and just $38 \mathrm{~km}$ from the capital Zagreb. NPP Paks is $90 \mathrm{~km}$ away from the Croatian border and 
$120 \mathrm{~km}$ from Osijek, which is the fourth largest city in Croatia and the largest city in Slavonia, the eastern part of Croatia.

The survey participants were asked to assess the level of risk that the nuclear power plants Krško and Paks represent to them and their families. Five answers have been offered: "High risk", "Medium risk", “Low risk", "No risk", and "Don't know". Twothirds of the participants believe that these nuclear power plants represent some level of risk ( $20.1 \%$ high risk, $26.1 \%$ medium risk, and $20.6 \%$ low risk), while only $13.8 \%$ believe that there is no risk to them and their families. Almost one out of five participants (19.4\%) selected the answer "Don't know" (Figure 8).

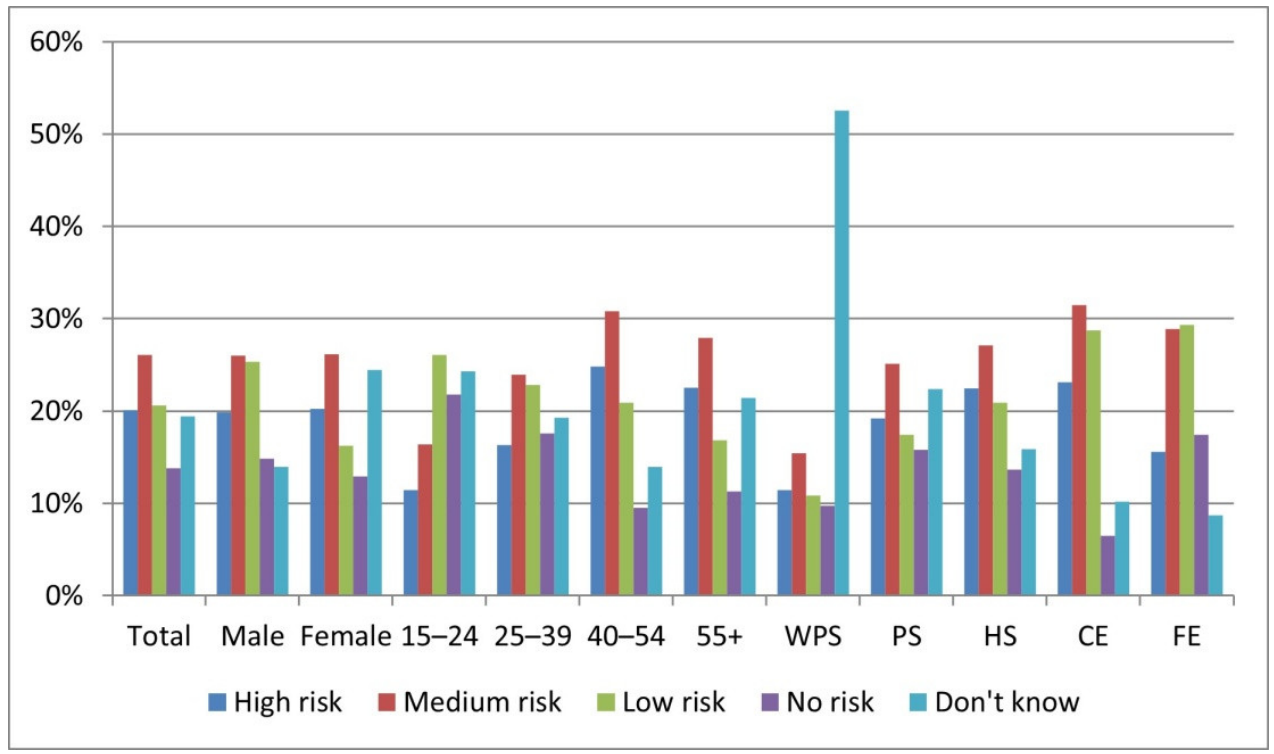

Figure 8. Perception of risk from the NPP Krško and the NPP Paks.

Almost the same share of the male and the female participants selected a high and medium level of endangerment, while a greater share of the males believe that the risk is low or that there is no risk at all. Females are more insecure on the level of risk than males, resulting in $24.5 \%$ of them selecting the answer "Don't know", compared to $13.9 \%$ of males. In general, the level of risk assessment increases with the participants' age for both genders as well as with their educational level with the partial exception of participants having a faculty education (FE). For FE participants, "High risk" and "Medium risk" shares decrease for $7.6 \%$ and $2.6 \%$, respectively, while the "Low risk" share remains almost unchanged compared to college education (CE) level participants.

It is interesting to notice that the regional distribution of opinions does not reveal any particular regularity. In an attempt to quantify the obtained data, each risk category has been given a value ranging from 5 for "High risk" down to 1 for "Don't know". The average risk grade for every county has been calculated by summing the participants' shares for each category multiplied by the corresponding category grade. The obtained average grades of the risk that the nuclear power plants Krško and Paks represent to the participants are graphically depicted in Figure 9. 


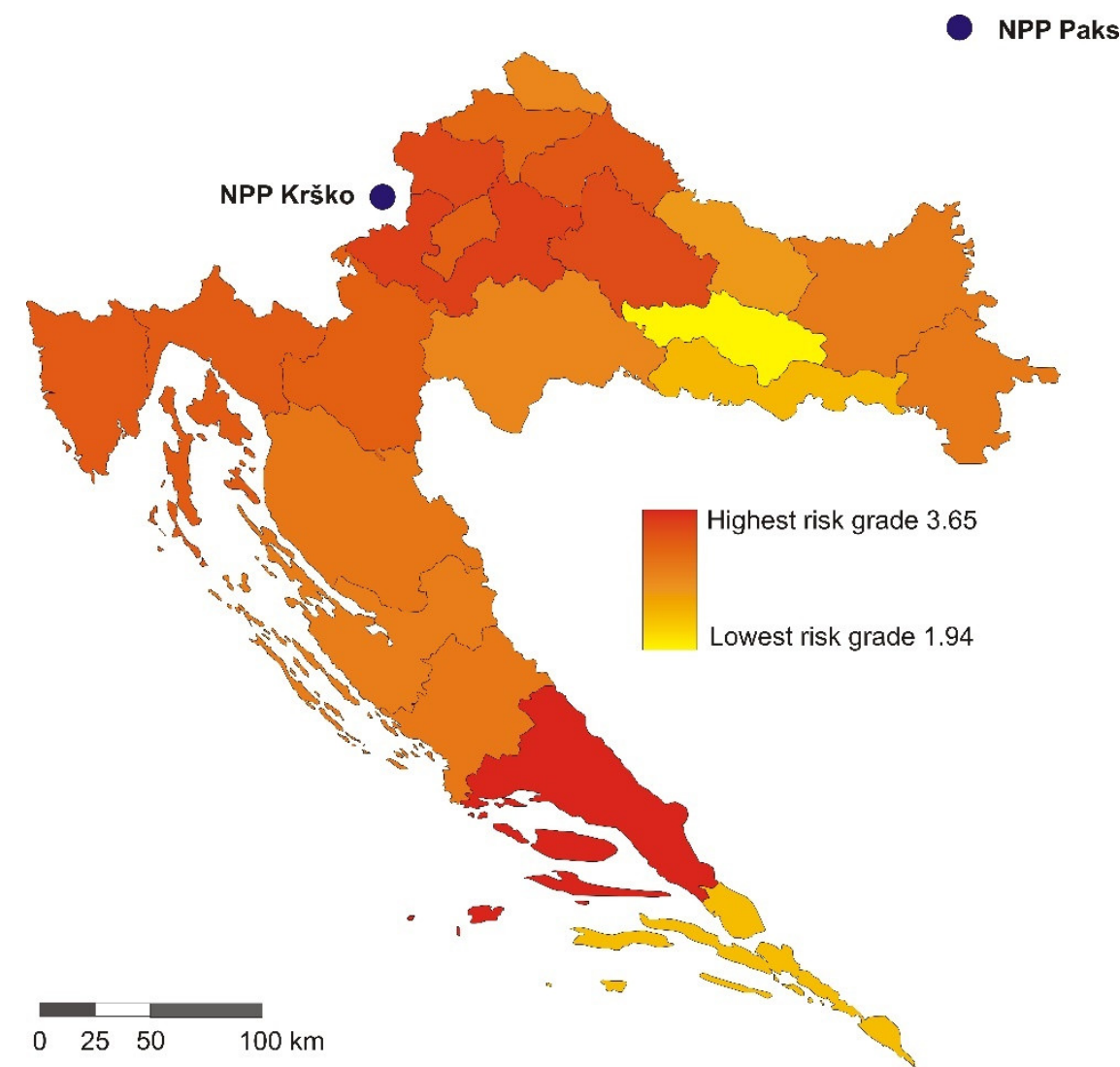

Figure 9. Average grades of the risk that the nuclear power plants Krško and Paks represent to the participants.

\subsection{Information Pathways, Trustworthy Sources, and the Level of Information}

For survey participants, the television $(79.9 \%)$, the Internet $(61.0 \%)$, and the radio (38.5\%) are the main sources of information on everyday events (Figure 10). No major deviations in the ranking status of different information sources have been observed based on regional, educational, and gender categories. However, it is interesting to take a closer look at the trends of three main sources with respect to age and educational groups. With the increase in age, the influence of radio and television also increases, while the opposite trend is noticeable for the internet. Younger and also more educated participants are more inclined to use the internet as their main source of information (Figure 11).

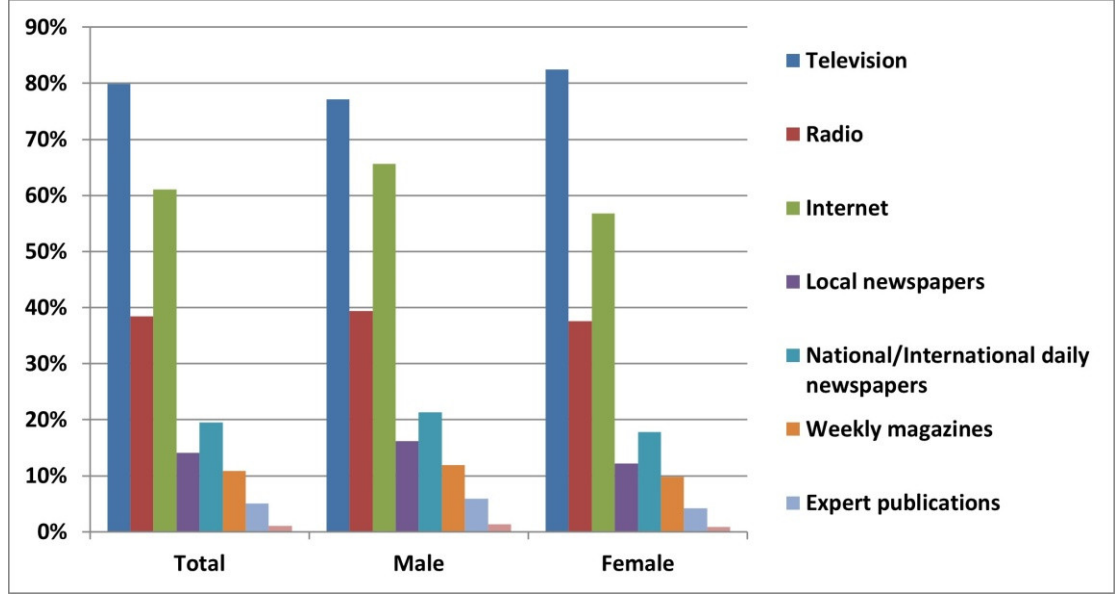

Figure 10. Main sources of general information. 


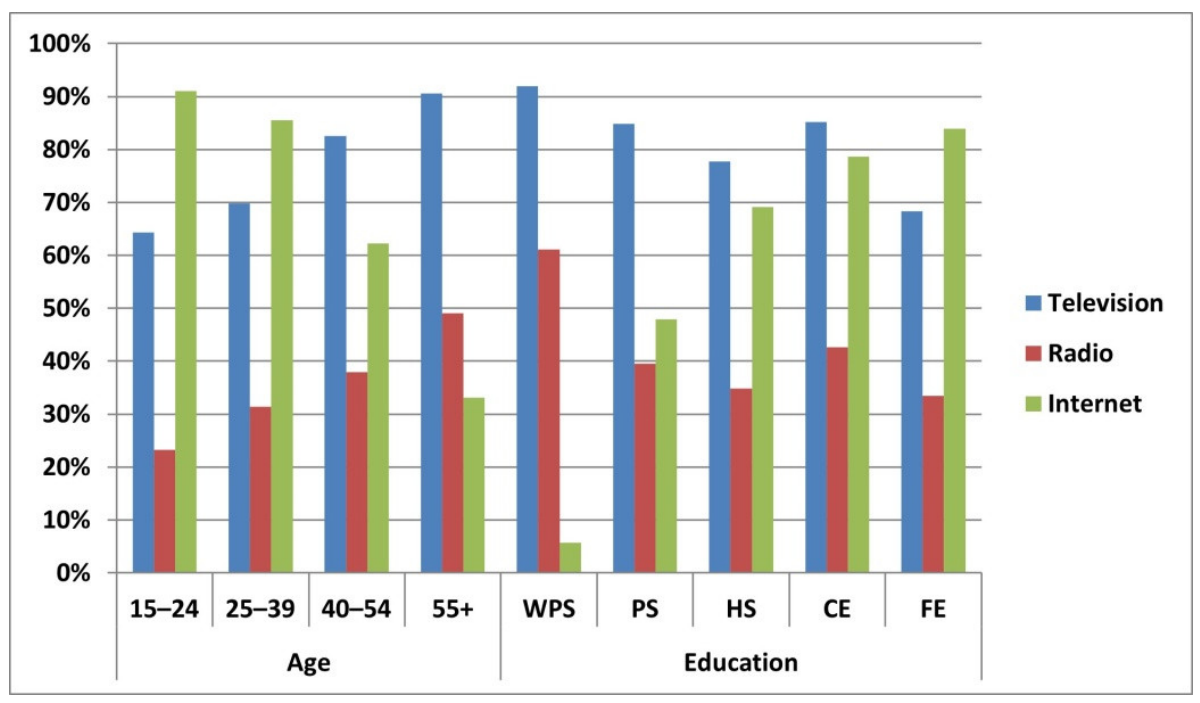

Figure 11. Age and education impact on main sources of general information.

Due to the slight differences in question formulation and a ten-year gap characterized by strong Internet development, a comparison of the Croatian and EU survey [13] is not viable.

Scientists with 63.6\%, the International Atomic Energy Agency (IAEA) with 45.9\%, and the national regulatory body-State Office for Radiological and Nuclear Safety (SORNS) with $42.1 \%$ have been chosen as the most trustworthy sources of information on nuclear energy and radioactive waste by survey participants (Figure 12). Journalists and the Croatian government were low ranked as trustworthy sources with just over $15 \%$ of participants selecting them, and the European Union (EU) as the trustworthy source of information was slightly better graded with a $24 \%$ selection share. It is important to emphasize that SORNS has been closed as an independent agency after the survey has been conducted. The responsibilities of SORNS have been transferred to the Ministry of Interior, Directorate of Civil Protection. It is an open question as to whether the public trust remains at high $42.1 \%$ or whether it dropped to $15 \%$, as was recorded for the Croatian government in general. The list of most trustworthy sources of information is not dependent on a regional or gender categorization of participants. However, the age and education of participants do have an influence on the list. The least educated participants mostly believe in the government, journalists, and EU institutions. With the increase in education, the trust in these three sources declines, especially the government and journalists (Figure 13). Government is trusted by only $9.3 \%$ of participants aged $15-24$, and the maximum trust in that particular source of $22.0 \%$ is observed for the oldest participants aged $55+$. The journalists' rank is even worse with $6.1 \%$ in the youngest group and $21.7 \%$ in the oldest group. A direct comparison of the Croatian and EU survey [13] is somewhat burned by the differences in choices of trustworthy sources given to participants to select from, but qualitatively, it can be performed. In general, EU participants when compared to Croatians show stronger trust toward the government (either national or regional) and journalists, while Croatians are more in favor of the national regulatory body, scientists, and the IAEA.

The survey participants were also asked to assess their level of information on the matter of nuclear power plant safety issues by selecting one out of six offered answers (Figure 14). The majority of the participants feel badly informed (46.6\%) or very badly informed $(17.0 \%)$ with only $4.9 \%$ feeling very well informed and $24.1 \%$ feeling well informed. Males generally feel more informed than females. There are some regional discrepancies with participants from Zagreb and Western Slavonia expressing a higher level of information than participants from Istria and Eastern Slavonia. Comparison to EU participants [13] reveals that Croatian participants are on the EU average. 


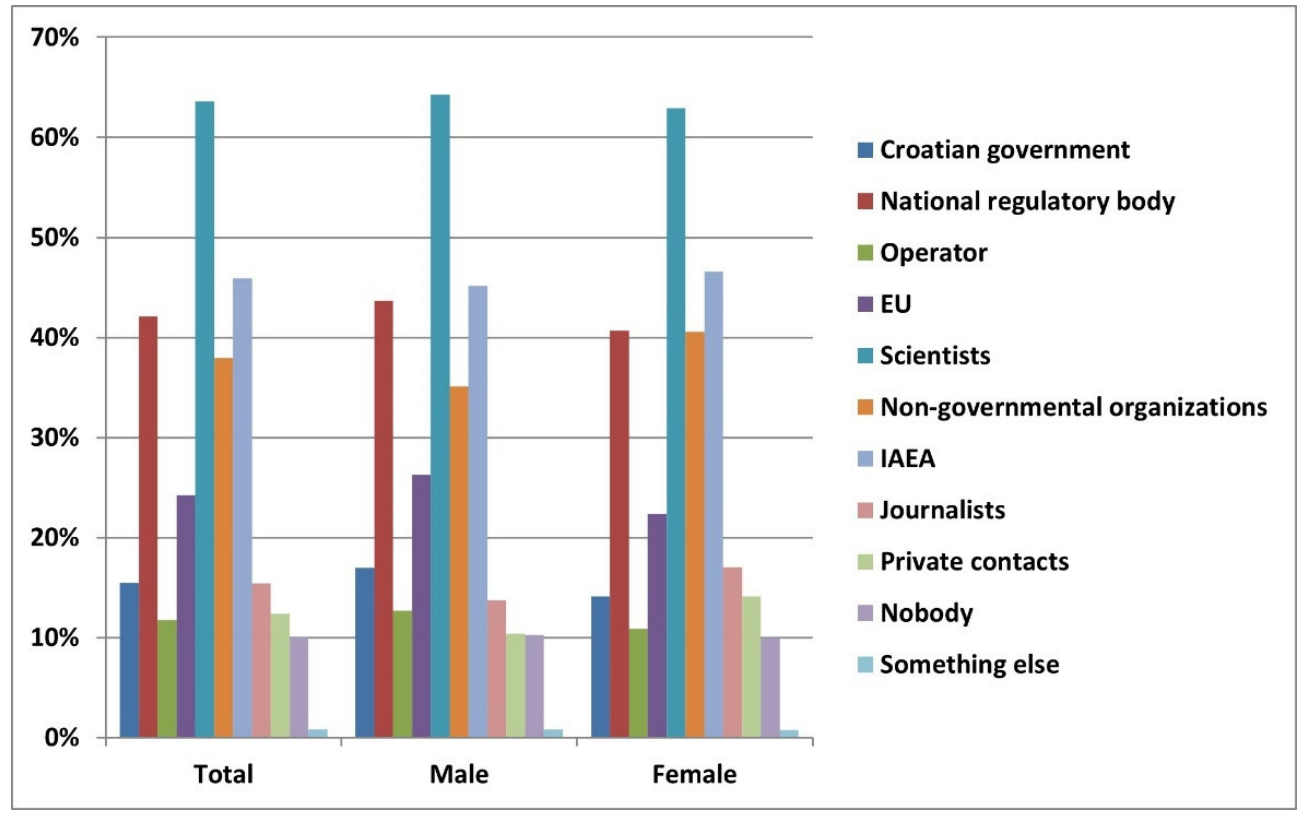

Figure 12. Trustworthy sources of information.

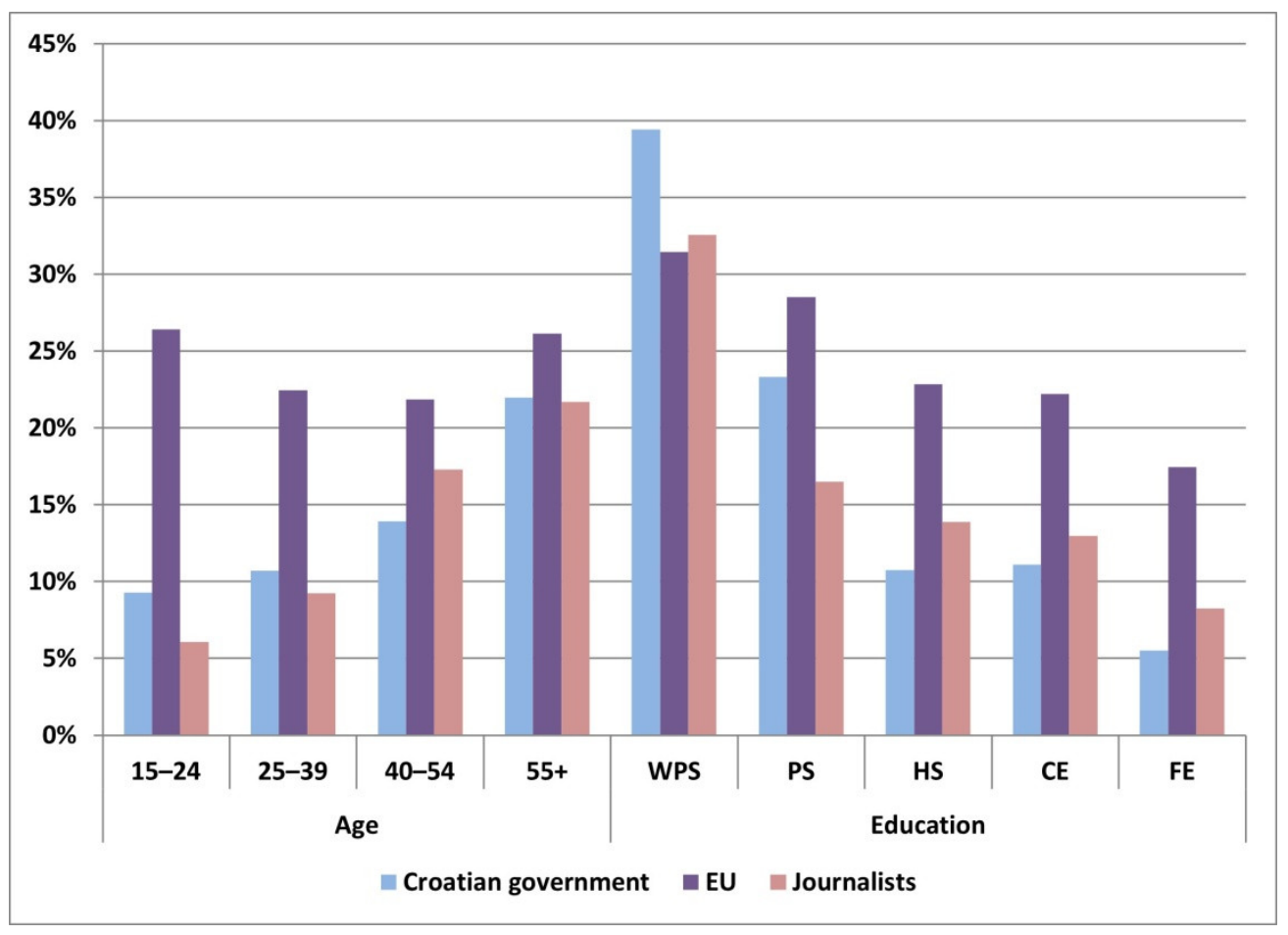

Figure 13. Age and education impact on selected sources of information.

\subsection{Brief Summary of RWM Survey Findings}

As stated earlier, the survey findings regarding radioactive waste management have been separately analyzed and published [23]. To enable better understanding of the overall nuclear issue in Croatia, a brief summary of RWM findings is presented. 


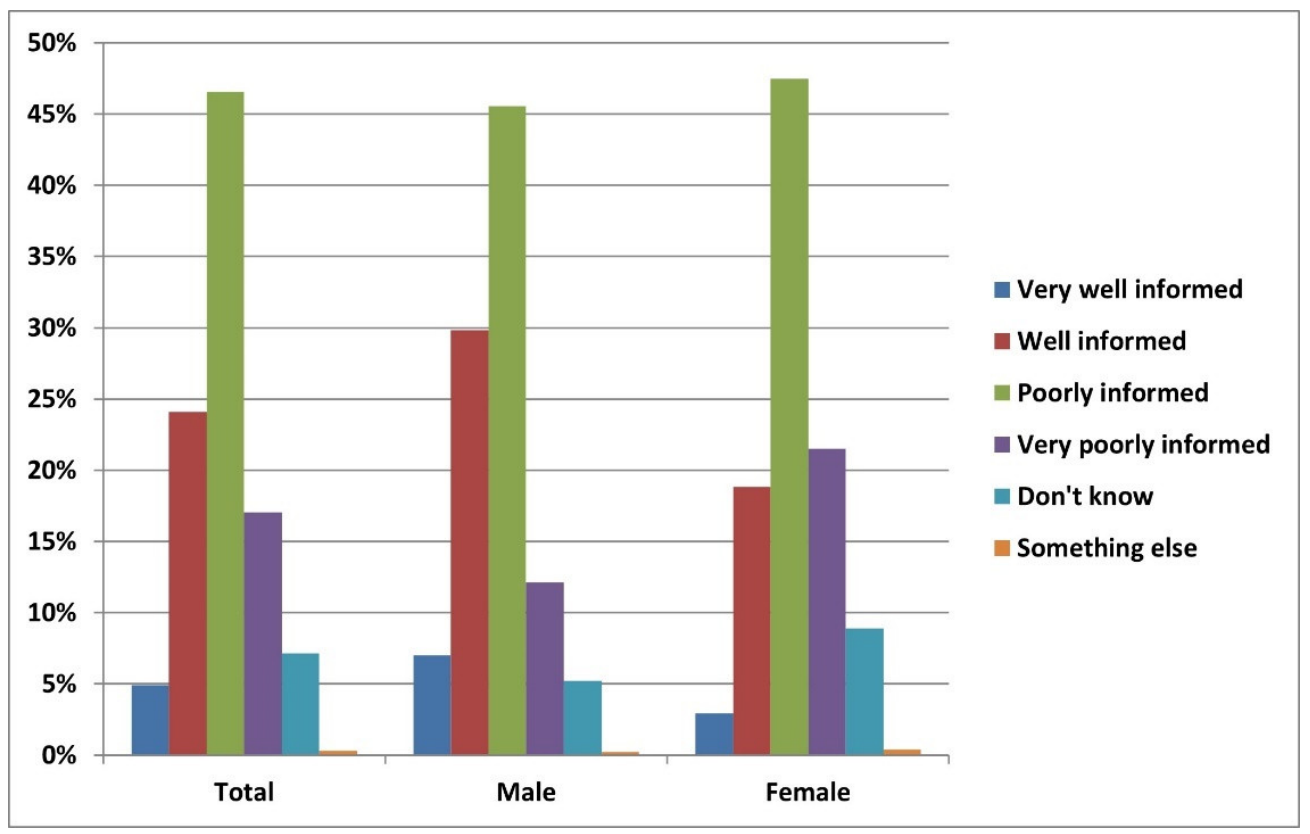

Figure 14. Participants' level of information on nuclear safety issues.

The level of knowledge in the population regarding general RWM issues is relatively satisfactory and within the EU average. However, the level of knowledge on the current status of RWM in Croatia is extremely low. Although an RWM legal framework exists, for the moment, Croatia does not have a central radioactive waste storage. Despite the fact that institutional radioactive waste is temporarily stored in two larger closed facilities located in the center of Zagreb and a number of end user sites, the focus of attention is on low and medium-level radioactive waste (LILW) originating from NPP Krško. Croatia has a legal obligation to manage half of that waste. Although larger in volume, the activity of NPP Krško LILW is smaller than the activity of institutional waste originating from Croatia. The opposition of the local community to the proposed central storage site is strong, and it is given a lot of media attention.

\section{Historical and Economic Factors Influencing Nuclear Option in Croatia}

As indicated in Section 2, our research is based on the assumption that the future Croatian position toward the nuclear option is influenced primarily by three factors: attitudes of the population, historical factors, and economic factors. In this section, we briefly discuss the latter two.

\subsection{Historical Factors}

Until 1991, Croatia was one of the former Yugoslavian republics. The nuclear program in former Yugoslavia started in the late 1940s and early 1950s and was centrally coordinated by the federal commission in three republics: Serbia as the center of political and military power and Slovenia and Croatia as the economically and industrially most advanced Yugoslavian republics. By the late 1960s, the federal commission was dismissed, and the development of a nuclear option for the energy sector was transferred to Slovenia and Croatian power utilities mostly due to inner political confrontation and military withdrawal from the nuclear project. The construction of the first nuclear reactor started in 1973 in Slovenia with at least one more nuclear power plant foreseen to be built in Croatia. Two sites in Croatia have been selected for detailed analysis, Prevlaka near Zagreb and Vir near Zadar for the first build, and Tenja near Osijek for the next build. Local authorities in Zadar did not approve the selection, and therefore, only the location in Prevlaka was considered for the first build [25]. By the late 1980s after the death of Yugoslavian president Josip Broz Tito and the accident at the Chernobyl power plant, the construction of all the 
NPPs in Yugoslavia was banned by the Law on the ban of the construction of nuclear power plants [26]. No restrictions have been imposed on nuclear research and scientific projects.

Before the proclamation of Croatian independence in October 1991, a series of legal acts on the takeover of Yugoslavian laws have been adopted to build new Croatian legislation. However, the law on the ban of nuclear build has never been officially taken over [25]. In 1992, the Croatian government adopted the Conclusion on the determination of criteria for the selection of locations for thermal and nuclear power plants [27]. Until 1997 and the end of war for independence, any idea of nuclear build was put aside. However, nuclear research and efforts on the education of nuclear engineers continued. In 1992, the Croatian Nuclear Society, the non-governmental organization promoting a peaceful application of nuclear energy, was also established. The first official sign of nuclear setback in Croatia was the adoption of the Croatian Spatial Planning Program in 1999 [28], which stated that no research on the possibilities of construction or actual build of thermal and nuclear power plants will be conducted until 2015. At the beginning of the 21st century, a series of laws and regulations on energy, energy market, and environmental impact assessment has been adopted. Each one had some articles related to nuclear power plants.

Crucial documents to analyze the evolution of the official position toward nuclear energy are the energy development strategies.

The energy development strategy from 2002 [29] addresses nuclear option as a potential after 2015 mainly for replacing old thermal power plants foreseen for shutdown. It is emphasized that nuclear is environmentally acceptable due to non-existing $\mathrm{SO}_{2}, \mathrm{NO}_{\mathrm{X}}$, and greenhouse gasses emission. It is also pointed that worldwide uranium resources are adequate. The need for assessment of operational safety and assessment of appropriate radioactive waste management is also emphasized.

The energy development strategy from 2009 [30] seemed as a new spark for the nuclear option. To quote: "Of all the observed measures, the application of nuclear energy is the measure with the greatest potential for reducing greenhouse gasses emission. It is estimated that without the increase in use of nuclear energy, it will not be possible to achieve the set goals of reducing greenhouse gasses emission. Disputes in the public regarding the impact on the environment, in particular the disposal of radioactive waste and spent nuclear fuel, will have to be agreed among all the stakeholders in order to enable greater use of nuclear energy". The strategy states that Croatia should start its nuclear program, and that the decision on whether a nuclear power plant will be built should be made by 2012. The strategy was supposed to be closely followed by a program of strategy implementation. The program was never adopted, and the decision on nuclear power plants was never made.

In the latest strategy from 2020 [31], nuclear energy is recognized as a low-carbon technology. However, the strategy only states that Croatia is dedicated to follow research on nuclear technology and consider the possible life extension of the NPP Krško beyond 2043. On the other hand, the strategy devotes a lot of attention to renewable energy sources. It is expected that the EU goal of $32 \%$ share of renewable energy will not only be met by 2030 but also exceeded by an additional 5\%.

Ever since the beginning of the nuclear program in Yugoslavia and the opening of the Ruđer Bošković Institute (RBI) in Zagreb in 1950, the nuclear research was present in Croatia. In the 1980s and 1990s, apart from the RBI, a very strong nuclear research group was active at Zagreb University, which mainly consisted of the Faculty of Electrical Engineering and Computing (FEEC). Together with their Slovenian colleagues, Croatian experts were also highly involved in all aspects of administrative and operational management of the NPP Krško. That cooperation is still present. FEEC was the educational center for nuclear engineers, many of whom were later on employed by the NPP Krško or Croatian Utility and governmental agencies responsible for administrative control of the NPP Krško. Nowadays, the FEEC is still educating nuclear engineers, but the number of students interested in the nuclear field is decreasing. That tendency was first noticed at the beginning of the 21 st century. Occasionally, there were some academic years with higher student response, but in general, the numbers are dropping. 
To summarize, it has to be noted that the development of the nuclear energy application in Croatia started while Croatia was a part of former Yugoslavia when NPP Krško was built as a joint effort of Slovenian and Croatian power utilities. The official Croatian politics never discarded the nuclear option, but neither fully proclaimed it as a viable one ever since Croatia became an independent state. The level of support varied throughout the years, currently being relatively low and backing just following current nuclear technology research. The academic and expert community in the area of interest is more than capable of not only following current research but also actively participating in it. However, a decrease in student interest in the nuclear subject is observed, which jeopardizes the future ability of Croatian academia to be active in the nuclear field.

\subsection{Economic Factors}

Based on available data [32,33], the Croatian total GDP in 2020 was 56.8 billion USD, while the GDP per capita was 14,101 USD with a slightly decreasing tendency. In the EU framework, Croatia is sharing the penultimate place alongside Greece, with Bulgaria being at the rear with the lowest GDP per capita. Based on Moody (Ba1 stable, from November 2020), Fitch (BBB stable, from April 2020), and S\&P (BBB stable, from March 2020) ratings, Croatia is at the boundary between non-investment and investment grade with speculative elements present and substantial credit risk. Overall, the Croatian government debt to GDP amounted to $88.7 \%$ of the country's GDP in 2020.

For the proceeding discussion, it would be useful to compare the Croatian and Slovenian general financial data. Based on available data [34], the Slovenian total GDP in 2020 was 52.9 billion USD, with the GDP per capita in the amount of 25,181 USD. The Slovenian credit rating is upper-medium-grade with a low credit risk, while the reported government debt is $80.8 \%$ of the GDP in 2020 .

The Croatian economy is highly reliable on tourism (approximately one-quarter of GDP), making the country vulnerable to various external shocks such as the current COVID19 pandemic. The industrial share in GDP is approximately $21 \%$. The leading industrial branches are the production of food, drinks, and tobacco, which is followed by the chemical and oil industries. In 2019, the largest export activities were related to food products, coke and oil products, pharmaceutical products, electrical equipment, machines and devices, and finished metal products.

The Croatian energy sector is highly dependent on imports. Based on the latest aggregated data for 2019 [35], Croatia has an export/import deficit for all energy forms, leading to a total of $329.4 \mathrm{PJ}$ import compared to $121.75 \mathrm{PJ}$ export. As far as electricity is concerned, in 2019, a total of 9158.3 GWh were imported and 3025.3 GWh were exported. It has to be noted that the electricity production in NPP Krško out of which $50 \%$ is Croatian is statistically treated as imported (2766.3 GWh). The overall demand for electricity in 2019 amounted to $18,893.3$ GWh. Out of approximately 12,700 GWh produced within Croatian borders, $46 \%$ originates from hydro power plants, $41 \%$ from thermal power plants (including biomass, biogas, and cogeneration), $11.5 \%$ from wind, and less than $1 \%$ from solar. Grouping renewable energy sources together (excluding large hydro) leads to the production of $2635 \mathrm{GWh}$ or $20.7 \%$ in share.

To summarize, in the EU context, Croatia is a below average country with low investment grade that is highly reliable on tourism as the main economy driver. The Croatian energy sector has an export/import deficit. In the electricity sector, almost one-fifth of consumption is imported, excluding electricity from NPP Krško.

\section{Discussion}

The official government position toward the nuclear option in the Croatian energy mix is clear from the latest energy development strategy as well as from the evolution of position stated in previous strategies going back almost 25 years. The slight opening to nuclear in the 2009 strategy with the proclamation of a nuclear program start is now put down to mere observation of up-to-date nuclear research. The in-house nuclear research 
is not banned, but it is also not encouraged. Such a position has a strong influence not only on the education of nuclear engineers but also on nuclear knowledge preservation. The pool of nuclear academic members built up in the early 1990s is reducing due to the natural retirement process but also due to the fact that many of them are changing their field of research.

Nuclear build is a demanding task requiring not necessarily an extremely strong but most of all a stable economy that could attract investment. The Croatian economy is at best a very modest one. With its current credit rating and general investment environment, it is hard to expect that the financial framework for a potential nuclear build could be achieved.

The largest influence on political decisions comes from continuous pressure from the general public. The Croatian public is not inclined to nuclear energy. It is perceived as a risky option, and nuclear build is not recognized as justified regardless of the possible reasons for such a build. The distance to nuclear power plants in Slovenia and Hungary does not influence the Croatian public which perceives them as a medium-risk threat. The Croatian public is poorly informed on RWM, especially on the current status of RWM in Croatia, which is highly influenced by NPP Krško LILW. The selection of trustworthy sources indicates an absolute lack of confidence in the government as a source of information.

A particular aspect of the possible Croatian nuclear future has to be discussed. As stated previously, Croatia owns 50\% of the NPP Krško in Slovenia, and electricity from that NPP is incorporated in Croatian electricity plans up to 2043 and planned shutdown and decommission of the facility. Ever since Slovenia proclaimed its dedication to build a second NPP, so-called JEK 2, there are opinions in Croatia that an alliance with Slovenia in a new nuclear enterprise should be considered. Depending on the fluctuation of the political relationship between the two countries, the idea of a joint nuclear build is gaining or losing position.

It has to be noted that recently, a number of pro-nuclear political addresses have been observed in Europe. Ten EU countries, including Croatia, in early October 2021 signed the initiative for a stronger EU shift to nuclear energy as an effective way of combating climate change and for decarbonization of the economy [36]. Just a few days later, the French President Emmanuel Macron announced a shift to small modular nuclear reactors as part of a 30 billion EUR, five-year strategy to stimulate the French high-tech industry [37]. In early November 2021, during the COP26 conference in Glasgow, the Croatian Prime Minister Andrej Plenković announced Croatia's intention to phase out coal not later than 2033 [38]. The latest political stand of the Croatian government regarding nuclear has yet to be fully processed by the Croatian public. At the moment, it does not change any of the previously stated facts, but it does indicate that follow-up of our investigation in the near future should be performed.

\section{Conclusions}

The purpose of the research reported on in this manuscript was to explore the factors influencing the possibility of nuclear energy expansion in Croatia. The main focus was on public opinion, which was graded as the most influencing factor. In addition, a brief overview of the historical and economic parameters affecting nuclear energy incorporation in the Croatian energy mix was also presented.

Taking into account the following findings, it can be concluded that change in Croatian non-nuclear orientation is highly unlikely:

- The Croatian public is not inclined to nuclear energy;

- The Croatian public does not consider the government as a trustworthy source of information;

- The Croatian public lacks knowledge on the current status of radioactive waste management and perceives LILW from NPP Krško as the main problem ignoring institutional radioactive waste;

- The latest national energy development strategy is clearly non-nuclear supportive; 
- The pool of academic nuclear experts is reducing the endangering education of nuclear experts and knowledge preservation;

- The economic status and investment environment in Croatia is low graded.

The possible joint nuclear enterprise with Slovenia in a JEK 2 build is at the moment of pure speculative nature.

The latest pro-nuclear political initiative in EU, in which Croatia is actively participating, has yet to be contemplated by the Croatian public. Further developments regarding that initiative will most likely trigger follow-up of our investigation on the position of Croatian public toward the nuclear option.

Author Contributions: Conceptualization, K.T. and D.P.; Formal analysis, K.T.; Investigation, R.J.; Methodology, K.T.; Resources, R.J.; Supervision, D.P.; Validation, M.M. and D.P.; Visualization, K.T.; Writing—original draft, K.T.; Writing—review and editing, M.M., D.P. and R.J. All authors have read and agreed to the published version of the manuscript.

Funding: This research received no external funding.

Institutional Review Board Statement: Not applicable.

Informed Consent Statement: Informed consent was obtained from all subjects involved in the study.

Data Availability Statement: Data is contained within this article and reference [22].

Conflicts of Interest: The authors declare no conflict of interest.

\section{References}

1. Saidi, K.; Omri, A. Reducing $\mathrm{CO}_{2}$ emissions in OECD countries: Do renewable and nuclear energy matter? Prog. Nucl. Energy 2020, 126, 103425. [CrossRef]

2. Rogner, H.-H.; Budnitz, R.; McCombie, C.; Mansouri, N.; Schock, R.; Shihab-Eldin, A. Keeping the Nuclear Energy Option Open, USAEE Working Paper No. 21-488. 2021. Available online: https://ssrn.com/abstract=3778835 (accessed on 20 November 2021).

3. McCalman, C.; Connelly, S. Destabilizing Environmentalism: Epiphanal Change and the Emergence of Pro-Nuclear Environmentalism. J. Environ. Policy Plan. 2019, 21, 549-562. [CrossRef]

4. European Council Conclusions, 12 December 2019. Available online: https://www.consilium.europa.eu/en/press/pressreleases/2019/12/12/european-council-conclusions-12-december-2019/ (accessed on 6 November 2021).

5. European Commission. Proposal for a Regulation of the European Parliament and of the Council Establishing the Just Transition Fund, January 2020. Available online: https:/ / eur-lex.europa.eu/legal-content/EN/TXT/PDF/?uri=CELEX:52020PC0022\& from=EN (accessed on 11 February 2021).

6. World Nuclear Association, Country Profiles. Available online: https://www.world-nuclear.org/information-library / countryprofiles.aspx (accessed on 11 February 2021).

7. Estonia Forms Working Group on Nuclear Energy. Available online: https://www.neimagazine.com/news/newsestonia-formsworking-group-on-nuclear-energy-8354308 (accessed on 11 February 2021).

8. Statista Research Department. GDP of Europe 2020, by Country. 26 July 2021. Available online: https://www.statista.com/ statistics / 613071/gdp-by-country-in-europe/ (accessed on 14 September 2021).

9. Renn, O.; Webler, T.; Rakel, H.; Dienel, P.; Johnson, B. Public participation in decision making: A three-step procedure. Policy Sci. 1993, 26, 189-214. [CrossRef]

10. Gupta, K.; Ripberger, J.T.; Fox, A.S.; Jenkins-Smith, H.C.; Silva, C.L. The future of nuclear energy in India: Evidence from a nationwide survey. Energy Policy 2021, 156, 112388. [CrossRef]

11. Wang, F.; Gu, J.; Wu, J. Perspective taking, energy policy involvement, and public acceptance of nuclear energy: Evidence from China. Energy Policy 2020, 145, 111716. [CrossRef]

12. Cho, I.; Oh, S.; Kim, S.; Ardin, F.; Heo, E. Determinants of nuclear power expansion in Indonesia. Nucl. Eng. Technol. 2021, 53, 314-321. [CrossRef]

13. TNS OPINION \& SOCIAL. SPECIAL Eurobarometer 324 Europeans and Nuclear Safety, March 2010. Available online: http: // / ec.europa.eu/public_opinion/archives/ebs/ebs_324_en.pdf (accessed on 11 February 2021).

14. TNS OPINION \& SOCIAL. SPECIAL Eurobarometer 297 Attitudes towards Radioactive Waste, June 2008. Available online: http:/ / / ec.europa.eu/public_opinion/archives/ebs/ebs_297_en.pdf (accessed on 11 February 2021).

15. Mostečak, A.; Ciglenečki, T.; Vejnović, Ž. Stav Javnosti o Potrebi Izgradnje Odlagališta Radioaktivnog Otpada u Republici Hrvatskoj. Rud.-Geološko-Naft. Zb. 2012, 24, 73-80. Available online: https:/ /hrcak.srce.hr/107814 (accessed on 12 February 2012).

16. Jakić, I.; Filipin, R. Analysis of public opinion survey Nuclear Energy-The present and the future (2000-2017). In Proceedings of the 12th International Conference of the Croatian Nuclear Society, Zadar, Croatia, 3-6 June 2018; pp. 166.1-166.11. 
17. Pejić Bach, M.; Pevec, D.; Baće, M.; Trontl, K.; Ječmenica, R.; Matijević, M.; Lebegner, J. Public Opinion Survey-Energy-The Present and the Future. In Proceedings of the 7th International Conference Nuclear Option in Countries with Small and Medium Electricity Grids, Dubrovnik, Croatia, 25-29 May 2008; pp. S.08.89.1-S.08.89.12.

18. Taherdoost, H. Sampling Methods in Research Methodology; How to Choose a Sampling Technique for Research. Int. J. Acad. Res. Manag. (IJARM) 2016, 5, 18-27. [CrossRef]

19. Croatian Bureau of Statistics. Census of Population, Households and Dwellings 2011. Available online: http://www.dzs.hr/ Eng/censuses/census2011/results/censusnames.htm (accessed on 12 February 2021).

20. Alwin, D.F. Margins of Error: A Study of Reliability in Survey Measurement, 1st ed.; Wiley-Interscience: Hoboken, NJ, USA, 2007.

21. Levy, P.S.; Lemeshow, S. Sampling of Populations: Methods and Applications, 4th ed.; Wiley-Interscience: Hoboken, NJ, USA, 2008.

22. Pevec, D.; Baće, M.; Trontl, K.; Matijević, M.; Ječmenica, R.; Dučkić, P.; Holjak, A. National Survey and Analysis of Public Opinion in Croatia on Nuclear Energy and Radioactive Waste Management. In Proceedings of the 26th International Conference Nuclear Energy for New Europe NENE2017, Bled, Slovenia, 11-14 September 2017.

23. Trontl, K.; Pevec, D.; Jakić, I.; Matijević, M. Radioactive waste management in Croatia-Public opinion, legal framework, and policy. Energy Policy 2020, 146, 111804.1-111804.13. [CrossRef]

24. Pevec, D.; Baće, M.; Trontl, K.; Matijević, M.; Ječmenica, R.; Dučkić, P.; Holjak, A. National Survey on Nuclear Energy and Radioactive Waste in Croatia. In Proceedings of the 26th International Conference Nuclear Energy for New Europe, Bled, Slovenia, 11-14 September 2017; Slovenian Nuclear Society: Ljubljana, Slovenia, 2017; pp. 1105.1-1105.18.

25. Feretić, D.; Čavlina, N.; Debrecin, N.; Grgić, D.; Bajs, T.; Jurković, I.A.; Medaković, S.; Bojić, K.; Iveković, I. Analysis of Previous Activities to Meet the Preconditions for the Introduction of the Nuclear Option in Croatia; Report no. FER-ZVNE/SR/DA-01/05-0; Nuclear Society of Slovenia: Zagreb, Croatia, 2005. (In Croatian)

26. Official Gazette SFRJ. The Law of the Ban on the Construction of Nuclear Power Plants; OG SFRJ 35/89; Official Gazette SFRJ: Zagreb, Croatia, 1989.

27. Official Gazette. Conclusion on the Determination of Criteria for the Selection of Locations for Thermal and Nuclear Power Plants. OG 78/92, 1992. Available online: https://narodne-novine.nn.hr/clanci/sluzbeni/1992_11_78_2042.html (accessed on 20 September 2021). (In Croatian)

28. Official Gazette. Croatian Spatial Planning Program. OG 50/99, 1999. Available online: https://narodne-novine.nn.hr/clanci/ sluzbeni/1999_05_50_944.html (accessed on 20 September 2021). (In Croatian)

29. Official Gazette. Croatian Energy Development Strategy. OG 38/02, 2002. Available online: https://narodne-novine.nn.hr/ clanci/sluzbeni/2002_04_38_839.html (accessed on 20 September 2021). (In Croatian)

30. Official Gazette. Croatian Energy Development Strategy. OG 130/09, 2009. Available online: https://narodne-novine.nn.hr/ clanci/sluzbeni/2009_10_130_3192.html (accessed on 20 September 2021). (In Croatian)

31. Official Gazette. Croatian Energy Development Strategy until 2030 with a View towards 2050. OG 25/20, 2020. Available online: https://narodne-novine.nn.hr/clanci/sluzbeni/2020_03_25_602.html (accessed on 20 September 2021). (In Croatian)

32. World Bank. The World Bank in Croatia, 2021. Available online: https:/ /www.worldbank.org/en/country/croatia/overview (accessed on 20 September 2021).

33. Trading Economics. Croatia Credit Rating. Available online: https://tradingeconomics.com/croatia/rating (accessed on 20 September 2021).

34. World Bank. The World Bank Country Profile Slovenia, 2021. Available online: https://databank.worldbank.org/views/reports/ reportwidget.aspx?Report_Name=CountryProfile\&Id=b450fd57\&tbar=y\&dd=y\&inf=n\&zm=n\&country=SVN (accessed on 20 September 2021).

35. Energy Institute Hrvoje Požar. Energy in Croatia 2019. 2020. Available online: http:/ /www.eihp.hr/wp-content/uploads/2020 /12/1_Energija_u_Hrvatskoj_2019-compressed-1.pdf (accessed on 23 September 2021).

36. HINA. Croatia among EU Member States Calling for Stronger Shift to Nuclear Energy, 11 October 2021. Available online: https:// www.total-croatia-news.com/politics /56813-croatia-among-eu-member-states-calling-for-stronger-shift-to-nuclear-energy (accessed on 6 November 2021).

37. Sebastian Seibt, France 24. France Unveils Nuclear Power Overhaul—With an Eye on China, 13 October 2021. Available online: https: / / www.france24.com/en/france/20211013-france-unveils-nuclear-power-overhaul-with-eye-on-china (accessed on 6 November 2021).

38. Croatian Government. Croatia Will Reduce CO2 Emissions by 45\% by 2030, Our Coal Phase-Out Year is 2033, 2 November 2021. Available online: https://vlada.gov.hr/news/pm-in-glasgow-croatia-takes-climate-change-seriously/33278 (accessed on 6 November 2021). 